\title{
Electrocatalytic Debromination of Organic Bromides Using a Cobalt(II)salen Complex in Ionic Liquids
}

\author{
Yi Shen, Toshiki TajIma, Mahito Atobe, and Toshio Fuchigami*
}

\author{
Department of Electronic Chemistry, Tokyo Institute of Technology (4259 Nagatsuta, Midori-ku, Yokohama 226-8502, \\ Japan)
}

Received June 29, 2004 ; Accepted September 11, 2004

\begin{abstract}
The catalytic effect of a Co(II)salen mediator on the reduction of cyclic vic-dibromide was investigated in ionic liquids by cyclic voltammetry. Macro-scale controlled potential electrolysis gave the corresponding debrominated product in moderate to good yields. The workup after electrolysis in an ionic liquid proved to be much simpler than that in organic solvents. The possibility of reuse of the ionic liquid was demonstrated to some extent.
\end{abstract}

Key Words : Mediator, Ionic Liquid, Controlled Potential Electrolysis

\section{Introduction}

Growing environmental awareness has spurred the search for alternatives to organic solvents for chemical synthesis. Recently, room temperature ionic liquids have attracted significant attention as 'green solvents', because of their low melting point, high polarity, negligible vapor pressure, non-flammability, ability to dissolve many materials, and good conductivity. ${ }^{1 !}$ Therefore, such nonvolatile ionic liquids seem to be ideal media for electrochemical organic synthesis." Sweeny and Peters reported the electrochemistry of nickel(II)salen in an ionic liquid. ${ }^{3}$ Furthermore, electroreductive coupling reaction of organic halides using a nickel complex was realized in ionic liquids. ${ }^{4}$ On the other hand, considerable attention has been focused on the reaction of electrogenerated cobalt(I) salen with organic halides. ${ }^{5-7}$ )

With these facts in mind, the electrochemistry of cobalt(II) salen, $\quad[N, N$ '-bis (salicylidene)-ethylenediaminocobalt(II) ] (Fig. 1) was investigated in various ionic liquids and its use for electrocatalytic reduction of a vic-dihalo compound was carried out.

\section{Experimental Section}

The starting material, 2,3-dibromo-1,2,3,4tetrahydronaphthalene (1) was prepared by the reaction of 1,4-dihydronaphthalene with bromine. Ionic liquids, 1ethyl-3-methylimidazolium tetrafluoroborate $\left(\mathrm{EMIMBF}_{4}\right)$, 1 -buthyl-3-methylimidazolium tetrafluoroborate $\left(\mathrm{BMIMBF}_{4}\right)$, 1-buthyl-3-methyl-imidazolium hexafluoro-

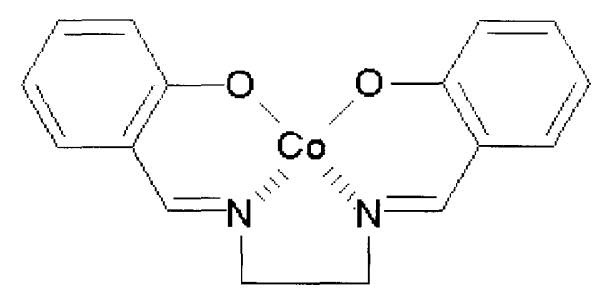

Fig. 1 Molecular structure of cobalt(II)salen. phosphate $\left(\mathrm{BMIMPF}_{6}\right)$ were purchased from Stella Chemifa Co., Inc., and Kanto Chemical Co., Inc. 1-Ethyl3-methylimidazolium trifluoromethanesulfonate (EMIMTfO) was obtained from Central Glass Co., Ltd. Cyclic voltammetric measurement was performed using a computer-controlled electrochemical system (ALS / CHI 600) with a three-electrode, two-compartment electrochemical cell. A glassy carbon disk $(\mathrm{d}=3 \mathrm{~mm})$ was used as a working electrode and a $P 1$ plate $(0 . . \times 0.5 \mathrm{~cm})$ as a counter electrode. The reference electrode was a saturated calomel electrode (SCE). The electrochemical cell and SCE were connected through a glass tube filled with the same ionic liquid as the cell medium.

Macro-electrolyses were carried out with a Hokuto Denko Corporation (HDC) model HA-501 potentiostatgalvanostat connected to a HDC model HF-201 coulomb/ amperehour meter. A DSA electrode $\left(\mathrm{RuO}_{2} / \mathrm{Ti}\right)$ was obtained from Permelec Electrode Ltd. The electrolytic cell is a conventional undivided cell equipped with a glassy carbon cathode $\left(2 \times 2 \mathrm{~cm}^{2}\right)$, an appropriate anode as shown in Table 1, and a SCE reference electrode.

The measurements and electrolyses were carried out under a nitrogen atmosphere. After electrolysis, the product in the ionic liquid was extracted three times with 10 $\mathrm{ml}$ of diethyl ether and evaporation of the extracts provided the product. The product was identified with an authentic sample which was purchased from Tokyo Kasei Kogyo Co., Ltd. The remaining ionic liquid was dried under vacuum for more than $6 \mathrm{~h}$ and was reused for the next electrolysis.

\section{Results and Discussion}

Cyclic voltammetric measurement of the Co(II)salen complex was performed in four kinds of ionic liquids such as EMIMBF 4 , EMIMTfO, BMIMBF 4 , and $\mathrm{BMIMPF}_{6}$. A well-defined reversible $\mathrm{Co}^{\mathrm{II}} / \mathrm{Co}^{1}$ redox couple of peaks was observed at $-1.23 \mathrm{~V}$ and $-1.15 \mathrm{~V}$ in BMIMBF$_{4}[$ Fig. 2 (a)] and a similar redox peaks was 


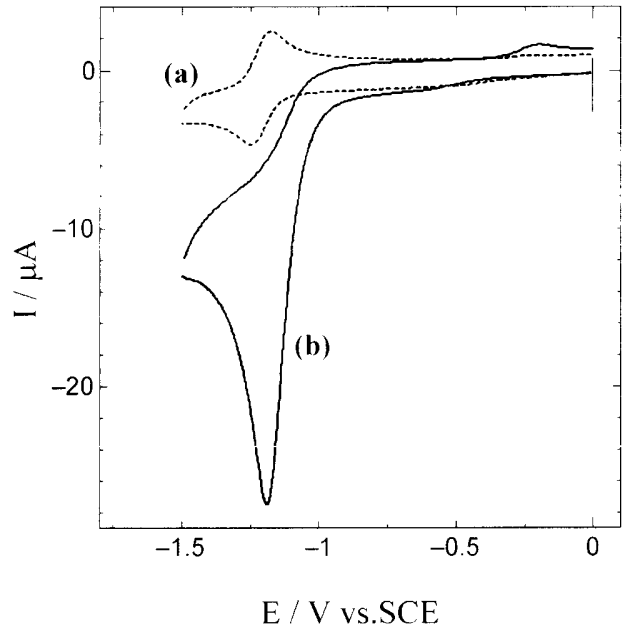

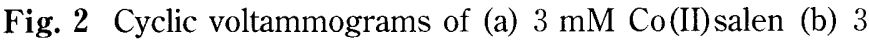
$\mathrm{mM}$ Co(II) salen in the presence of $5 \mathrm{mM}$ 2,3-dibromo-1,2,3,4tetrahydronaphthalene $(\mathbf{1})$ at $\mathrm{GC}$ electrode $(\mathrm{d}=3 \mathrm{~mm})$ in $\mathrm{BMIMBF}_{4}$. Scan rate $: 100 \mathrm{mV} \mathrm{s}^{-1}$.

also observed at $-1.18 \mathrm{~V}$ and $-1.10 \mathrm{~V}$ in $\mathrm{EMIMBF}_{4}$. The peak separation was $80 \mathrm{mV}$ and the redox peak currents were almost identical in both ionic liquids. On the other hand, no clear redox peaks were observed in EMIMTFO and BMIMPF ${ }_{6}$.

Figure 2 shows the cyclic voltammogram of Co(II) salen in the absence (curve a) and presence of 2, 3 dibromo-1,2,3,4-tetrahydronaphthalene (1) (curve b) in ionic liquid $\mathrm{BMIMBF}_{4}$.

The cathodic peak current of Co(II) salen increased markedly after addition of the dibromide 1 while the anodic oxidation peak disappeared completely. Since the reduction potential $\left(\mathrm{E}_{\mathrm{p}}^{\mathrm{red}}\right.$ ) of $\mathbf{1}$ is $-1.91 \mathrm{~V}$ vs. SCE in $\mathrm{BMIMBF}_{4}$, the enhanced cathodic current of $\mathrm{Co}(\mathrm{II})$ salen suggests electrocatalytic reduction of $\mathbf{1}$ with the electrogenerated $\mathrm{Co}(\mathrm{I})$ complex would take place. Hence, controlled-potential electrolysis of 1 was carried out using the Co(II) salen complex as a mediator in $\mathrm{BMIMBF}_{4}$ at $-1.3 \mathrm{~V}$ vs. SCE, where $\mathbf{1}$ can not be reduced at all. Furthermore, the effect of anode materials on the yield of the cathodic reduction product of 1 was investigated. The electrolytic results are shown in Table 1 . When a platinum plate was used as an anode, the reduction product, 1,4-dihydronaphthalene (2) was formed solely in 38\% of yield (Table 1, Entry 1). The use of a sacrificial aluminum anode resulted in comparable yields as obtained at a Pt anode (Table 1, Entry 2). When an iron (Fe) plate was used as a sacrificial anode, the yield of product 2 increased to a moderate value of $53 \%$ (Entry 3 ). However, in this case, the electrolyte became very dark and viscose after electrolysis, and unidentified precipitates were observed. When DSA was employed as an anode, the yield of compound 2 was increased to about $70 \%$ (Entry 4). The use of a DSA anode accelerated anodic oxidation of bromide ions to bromine, which may suppress the decomposition of the ionic liquid. For comparison, the electrolysis was also carried out in DMF using $\mathrm{Bu}_{4} \mathrm{NBF}_{4}$ as a supporting electrolyte. Although the yield of 2 obtained in DMF (Table 1, Entry 5) was a little higher than that in
Table 1 Effect of anode materials on electrocatalytic reduction of vic-dibromide 1 in ionic liquid.a)

\begin{tabular}{ccc}
$\mathbf{1}$ & $\begin{array}{c}\text { GC cathode } \\
\text { in BMIMBF }\end{array}$ \\
\hline Entry & Material of anode & Yield of $2(\%)$ \\
\hline 1 & $\mathrm{Pt}$ & 38 \\
2 & $\mathrm{Al}$ & 40 \\
3 & $\mathrm{Fe}$ & 53 \\
4 & $\mathrm{DSA}$ & 68 \\
$5^{\text {b) }}$ & $\mathrm{DSA}$ & 73 \\
\hline
\end{tabular}

a) Electrolytic conditions: substrate $1,0.5 \mathrm{mmol}$ in $10 \mathrm{ml}$ $\mathrm{BMIMBF}_{4}$; $\mathrm{Co}_{0}$ (II) salen, 0.05 equiv.; electrolysis potential, $-1.3 \mathrm{~V}$ vs. SCE; charge passed, $4 \mathrm{~F} \mathrm{~mol}^{-1}$.

b) Electrolysis in $0.1 \mathrm{M} \mathrm{Bu}_{4} \mathrm{NBF}_{4} / \mathrm{DMF}$.

Table 2 Reuse of $\mathrm{Co}_{0}$ (II) salen and ionic liquid $\mathrm{BMIMBF}_{4}$ for electrocatalytic reduction of vic-Dibromide $2 .{ }^{\text {a) }}$

\begin{tabular}{cc}
\hline Cycle & Yield of $2(\%)$ \\
\hline $1^{\text {st }}$ & 68 \\
$2^{\text {nd }}$ & 52 \\
$3^{\text {rd }}$ & 37 \\
$4^{\text {th }}$ & $69^{\mathrm{b})}$
\end{tabular}

a) $4 \mathrm{~F} \mathrm{~mol}^{-1}$ was passed.

b) 0.05 equiv. $\mathrm{Co}$ (II) salen was added again.

the ionic liquid (Entry 4), the workup after the electrolysis of 1 proved to be a big problem: It is rather difficult to remove the supporting electrolyte $\mathrm{Bu}_{\mathrm{NBF}}$ and $\mathrm{Co}$ (II) salen complex from the product. However, in the case of the electrolysis in ionic liquid, the product was extracted conveniently by diethyl ether and Co(II) salen mediator remained in the phase of the ionic liquid. The remaining mediator could be reused for the next electrocatalytic debromination of 1 .

In order to demonstrate the advantages of using an ionic liquid, we examined the possibility of the reuse of both the Co(II) salen mediator and the ionic liquid. After the electrolysis of 1 in $\mathrm{BMIMBF}_{4}$, the ionic liquid was readily recovered simply by extracting the product 2 with diethyl ether and then the recovered ionic liquid was dried under vacuum for $6 \mathrm{~h}$ to remove remaining ether and moisture and was reused for the next electrolysis. The second electrolysis was carried out in the recovered ionic liquid, where only the substrate was added. The experimental results are listed in Table 2 . The yield was decreased from the first cycle $(68 \%)$ to the third cycle $(37$ $\%$ ). Since the loss of $\mathrm{Co}$ (II) salen during the workup procedure can be disregarded, this sharp decrease of the yield seems to be attributable to the deactivation and decomposition of Co(II) salen during the electrolysis. However, when 0.05 equiv. of $\mathrm{Co}$ (II) salen was newly added with the substrate 1 before electrolysis, the yield of 2 increased to $69 \%$ (Table $2,4^{\text {th }}$ cycle), which is almost the same yield as in the first cycle.

In consideration of the reported mechanism for electrocatalytic reduction of organic halides with similar complexes, ${ }^{7,8)}$ a reaction mechanism can be proposed as 


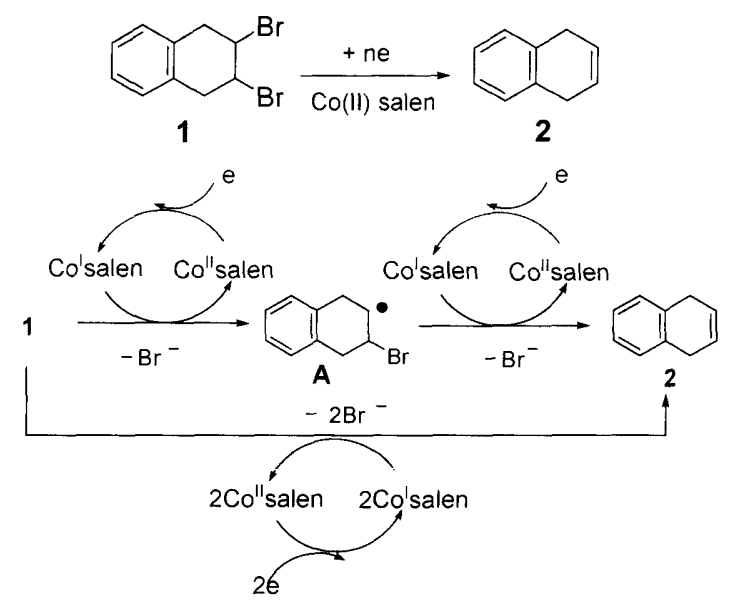

Scheme 1

shown in Scheme 1. One-electron reduction of Co(II) salen generates $\mathrm{Co}(\mathrm{I})$ salen, which reacts with the starting dibromide $\mathbf{1}$ to form intermediate $\mathbf{A}$ and a bromide ion. Successively, A reacts again with electrogenerated Co(I) salen to provide 1,4-dihydronaphthalene (2). In addition to the above stepwise process, electrocatalytic reduction of 1 with two equivalents of electrogenerated $\mathrm{Co}$ (I) salen to give 2 directly is also possible.

\section{Conclusion}

In summary, the electroreductive debromination was successfully carried out using a Co(II)salen complex as a

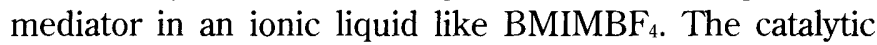
effect of the Co(II) salen mediator on the reduction of vicdibromide was investigated in an ionic liquid by cyclic voltammetry. Macro-scale controlled potential electrolysis gave the corresponding debrominated product in moderate to good yields. The workup after the electrolysis in the ionic liquid proved to be much simpler than that in usual conventional organic solvents. The possibility of the reuse of the ionic liquid was demonstrated to some extent. Further efforts for the reuse of the ionic liquid and mediator are now in progress.

\section{References}

1) (a) A. E. Visser, R. P. Swatloski, and R. D. Rogers, Green Chem., 2, 1, 2001; (b) T. Welton, Chem. Rev., 99, 2071 (1999).

2) (a) H. Ishii and T. Fuchigami, Electrochemistry, 70, 46 (2002); (b) T. Fuchigami, Electrochemical Aspects of Ionic Liquids, H. Ohno (ed.), John Wiley \& Sons, 2004, Chapter 4; (c) M. Hasegawa, H. Ishii, and T. Fuchigami, Green Chem., 5, 512 (2003).

3) B. K. Sweeny and D. G. Peters, Electrochem. Commun., 3, 712 (2001).

4) (a) M. Mellah, S. Gmouh, M. Vaultier, and V. Jouikou, Electrochem. Commun., 5, 591 (2003); (b) Barhdadi, R. Courtinard, C. Nedelec, and J. Y. Troupel, M. Chem. Commun., 2003, 1434.

5) (a) A. Isse, Gennaro, and E. Vianello, J. Electroanal. Chem., 444, 241 (1998); (b) M. J. Samide and D. G. Peters, J. Pharm. Biomed. Anal., 19, 193 (1999); (c) K. S. Alleman and D. G. Peters, J. Electroanal. Chem., 451, 121 (1998); (d) K. S. Alleman and D. G. Peters, J. Electroanal. Chem., 460, 207 (1999).

6) (a) Y. Hisaeda, H. Shimakoshi, A. Nakazato, and T. Hayashi, Organic Electrochemistry, The Electrochemical Society, eds. By M. S. Workentin, F. Maran, and K. Chiba, Vol. 2002-10, 48 (2002); (b) Y. Hisaeda, New Developments in Organic Electrosynthesis, CMC, ed. By T. Fuchigami, 2004, Chapter 6; (c) D. -L. Zhou, H. Carrero, and J. F. Rusling, Langmuir, 12, 3067 (1996).

7) L. Gaillon and F. Bedioui, J. Mol. Catal. A, 214, 91 (2004).

8) J. F. Rusuling, C. L. Miaw, and E. C. Couture, Inorg. Chem., 29, 2025 (1990). 